\title{
Focus on Fertility Preservation
}

\section{Hormonal suppression for fertility preservation in males and females}

\author{
Marvin L Meistrich and Gunapala Shetty \\ Department of Experimental Radiation Oncology, MD Anderson Cancer Center, The University of Texas, 1515 \\ Holcombe Boulevard, Houston, Texas 77030, USA
}

Correspondence should be addressed to G Shetty; Email: sgunapal@mdanderson.org

\begin{abstract}
Methods to restore fertility of men and women sterilized by medical treatments and environmental toxicant exposures are under investigation. Rendering spermatogenesis and ovarian follicular development kinetically quiescent by suppression of gonadotropins has been proposed to protect them from damage by cytotoxic therapy. Although the method fails to protect the fertility of male mice and monkeys, gonadotropin and testosterone suppression in rats before or after cytotoxic therapy do enhance the recovery of spermatogenesis. However, the mechanism involves not the induction of quiescence but rather the reversal, by suppression of testosterone, of a block in differentiation of surviving spermatogonia caused by damage to the somatic environment. In men, only one of eight clinical trials was successful in protecting or restoring spermatogenesis after cytotoxic therapy. In women, protection of primordial follicles in several species from damage by cytotoxic agents using GnRH analogs has been claimed; however, only two studies in mice appear convincing. The protection cannot involve the induction of quiescence in the already dormant primordial follicle but may involve direct effects of $\mathrm{GnRH}$ analogs or indirect effects of gonadotropin suppression on the whole ovary. Although numerous studies in female patients undergoing chemotherapy indicate that GnRH analogs might be protective of ovarian function, none of the studies showing protection were prospective randomized clinical trials and thus they are inconclusive. Considering interspecies differences and similarities in the gonadal sensitivity to cytotoxic agents and hormones, mechanistic studies are needed to identify the specific beneficial effects of hormonal suppression in select animal models that may be applicable to humans.
\end{abstract}

Reproduction (2008) 136 691-701

\section{Introduction}

Medical treatments required for life-threatening diseases such as cancer or exposure to environmental toxicants may jeopardize the fertility of men and women of reproductive age. In men, such exposures can lead to effects ranging from temporary oligospermia to permanent azoospermia, and occasionally to androgen insufficiency. In women, such exposures can result in a range of effects from temporary amenorrhea to premature menopause and permanent amenorrhea, with the associated estrogen insufficiency. Whereas transient effects do affect the quality of life, the most serious effects of concern are the irreversible permanent effects.

Methods to prevent these effects on fertility and to restore gonadal function after the toxic treatment are of great importance to men and women of childbearing age. A variety of biochemical and biological approaches (thiol radioprotectors, prostaglandin analogs, growth factors, blockers of apoptotic pathways, and reduction in blood flow) have been tested to protect the testes in experimental animal model systems against radiation and chemotherapy (reviewed in Meistrich et al. 2007). However, the greatest research interest and nearly all clinical trials have involved hormonal modulation in attempts to prevent or reverse damage to the germ line from radio- and chemotherapy. We will discuss the present status of the knowledge on the hormonal suppression as a means to preserve fertility in men and women separately.

\section{History and hypotheses}

The use of hormonal suppression for protecting gonadal function after cytotoxic exposure is based on the observation that non-cycling cells are generally more resistant to killing by certain toxicants, particularly antineoplastic agents, than are rapidly proliferating cells. The greater sensitivity of cycling when compared with non-cycling cells is the basis for the antitumor action of many of these antineoplastic agents.

The mechanism originally proposed for the protection of spermatogenesis was that interruption of the 
pituitary-gonadal axis would reduce the rate of spermatogenesis and render the resting testis more resistant to the effects of chemotherapy (Glode et al. 1981). Although the Glode study claimed that pretreatment with gonadotropin-releasing hormone $(\mathrm{GnRH})$ protected spermatogenesis in the mouse from damage by cyclophosphamide, attempts to repeat these original observations using more quantitative endpoints revealed that there was no protection (da Cunha et al. 1987). Since suppression of gonadotropins and testosterone only blocks the completion of spermatogenesis but has no effect on the kinetics of the developing cells (Meistrich et al. 1997), the premise on which the mechanism was based was incorrect and the negative outcome should be expected. Furthermore, the stem spermatogonia, which are more important targets than the differentiating germ cells for the longterm effects of cytotoxic damage, did not appear to be affected at all by hormonal suppression.

Despite the failure until now to observe protective effects in mice, it has been convincingly shown that suppression of gonadotropin and intratesticular testosterone levels prior to or during exposure of rats to chemotherapy or radiation enhances the subsequent recovery of spermatogenesis (Delic et al. 1986). Thus, other mechanisms must be involved and careful attention must be given to the species used.

Similarly suppression of gonadotropins with $\mathrm{GnRH}$ agonists or steroidal oral contraceptives has been proposed to suppress ovarian function, specifically to halt follicular development and follicular cell division, with the goal of protecting these currently dormant ovarian follicles from destruction (Chapman \& Sutcliffe 1981, Ataya et al. 1985). However, gonadotropins act primarily on the cyclic recruitment of antral follicles, while the initial recruitment of primordial follicles is not directly controlled by gonadotropins (McGee \& Hsueh 2000). It is these primordial follicles that provide the source for the long-term growing follicle and ova production and thus should be the target for protection. They lack gonadotropin receptors and besides are normally non-proliferating. Furthermore, although ovaries contain $\mathrm{GnRH}$ receptors, there is no evidence for the presence of $\mathrm{GnRH}$ receptors on primordial follicles (Danforth et al. 2005).

Although several early studies concluded that such suppressive treatments could protect rat ovarian follicles against the damaging effects of chemotherapy (Ataya et al. 1985, Bokser et al. 1990), these results did not show that primordial follicles were protected (Meistrich 1994). Recent studies using a GnRH agonist (Danforth et al. 2005) or an antagonist (Meirow et al. 2004) do however show protection of primordial follicles in mice from the damaging effects of cyclophosphamide. However, the originally proposed mechanism does not appear to be valid.

\section{Experimental studies - males}

The generally accepted model for the male gonadal toxicity from antineoplastic agents is that actively dividing differentiated spermatogonia are most sensitive to these agents, which will lead to a reduction in the sperm count. The reduction should be temporary provided the stem spermatogonia survive. However, stem spermatogonia are killed by some of these agents at varying degrees and recover only gradually, resulting in prolonged reductions of sperm count; in the mouse, this reduction is directly related to stem cell killing (Meistrich 1982). It is rare that surviving stem spermatogonia fail to differentiate in mouse testes (Kangasniemi et al. 1996b). By contrast, after exposure of rats to several antineoplastic agents (Kangasniemi et al. 1996a) and other toxicants (Boekelheide \& Hall 1991), the stem spermatogonia that survive are blocked from differentiating and their progeny undergo apoptosis instead (Meistrich \& Shetty 2003). This block has been shown to be a result of damage to the somatic environment within the testis, not to the spermatogonia (Zhang et al. 2007). There is, however, no evidence of a similar spermatogonial block in monkeys (Boekelheide et al. 2005).

Several studies further support the conclusion that gonadotropin suppression does not protect spermatogenesis from damage in mice (Nonomura et al. 1991, Kangasniemi et al. 1996b, Crawford et al. 1998). By contrast, numerous reports suggest that hormonal suppression protects rat testes from damage due to irradiation, procarbazine, doxorubicin, an indenopyridine compound, and heating (Delic et al. 1986, Morris \& Shalet 1990, Jégou et al. 1991, Parchuri et al. 1993, Kangasniemi et al. 1995, Weissenberg et al. 1995, Manabe et al. 1997, Hild et al. 2001, Setchell et al. 2002) and enhances future fertility in the face of these toxicants. In addition to direct suppression of gonadotropins with $\mathrm{GnRH}$ agonists or antagonists, which also results in both direct and secondary suppression of intratesticular testosterone, these studies also utilized combinations of $\mathrm{GnRH}$ analogs with antiandrogens, systemic physiological doses of testosterone (which suppresses gonadotropins and results in reduced intratesticular testosterone levels), progestins (which are very effective at suppressing gonadotropins but have weak androgenic activity), and estrogens (which both suppress gonadotropins and inhibit testosterone synthesis). It should be noted that in all these studies protection was not assessed directly at the time of cytotoxic exposure, but rather by the enhanced ability of spermatogenesis to recover from surviving stem cells (Meistrich et al. 2000), which is actually the most relevant endpoint for future fertility.

Attempts to protect spermatogenesis in other animal species (dog and monkey) have not yielded any reproducible positive results. Although one group reported that $\mathrm{GnRH}$ agonist shortened the time to recovery of spermatogenesis after treatment of dogs 
with cyclophosphamide, cisplatin, or radiation (Nseyo et al. 1985), another study reported potentiation of the damage (Goodpasture et al. 1988). Similarly, one preliminary report based on an extremely small number of baboons suggested that GnRH agonists might decrease the gonadal damage from cyclophosphamide (Lewis et al. 1985), while larger studies showed neither protection nor stimulation of recovery of spermatogenesis in macaques from radiation damage by $\mathrm{GnRH}$ antagonist treatment (Kamischke et al. 2003, Boekelheide et al. 2005).

We proposed that prevention of the pronounced block in differentiation of surviving stem spermatogonia in rat testes after exposure to cytotoxic agents (Fig. 1A and B) is the mechanism by which hormonal suppression appears to protect spermatogenesis from toxicant exposure (Meistrich et al. 2000). It is important to note that many of the studies showing protection involved subchronic exposure to the cytotoxic agent, so the hormonal suppression was given after the initial exposures, and in some cases even extended beyond the last exposure (Pogach et al. 1988). Furthermore, when the hormonal suppression was administered to the rats only after the cytotoxic insult, either immediately or after a delay (Fig. 1C), the numbers of differentiated germ cells still dramatically increased (Meistrich \& Kangasniemi 1997). However, because testosterone, which is required for spermatid differentiation, was suppressed, spermatogenesis proceeded only to the round spermatid stage: no sperm were produced. Nevertheless, when additional time without further suppressive treatment was allowed before the rats were killed, all tubules showed almost complete spermatogenic recovery, sperm counts increased, and the fertility of the rats significantly increased (Meistrich et al. 2001). This phenomenon appears to be quite general: posttreatment with GnRH agonists or antagonists, with or without antiandrogen, low-dose systemic testosterone, estradiol, or hypophysectomy are all effective at stimulating recovery (Shetty et al. 2002, 2006), and recovery has been stimulated following gonadal toxicity from anticancer agents, such as radiation, procarbazine (Meistrich et al. 1999), or busulfan (Udagawa et al. 2001), and environ- mental toxicants, such as hexanedione (Blanchard et al. 1998) or dibromochloropropane (Meistrich et al. 2003), an indenopyridine compound (Hild et al. 2001), or heat treatment (Setchell et al. 2001). The endogenous hormone primarily responsible for the inhibition of spermatogonial differentiation in toxicant-treated rats was testosterone, although follicle-stimulating hormone (FSH) also had a minor inhibitory effect (Shetty et al. 2006), and other exogenously administered androgens were also inhibitory (Shetty et al. 2002). We have also observed that hormonal suppression after irradiation of mouse testes modestly but highly significantly increased the percentage of tubules in which differentiation of surviving spermatogonia occurred (R A Wang \& M L Meistrich, unpublished observations).

Hormonal suppression with $\mathrm{GnRH}$ analogs or hypophysectomy has also been shown to promote the survival and differentiation of spermatogonia that are transplanted into testes of animals that were depleted of endogenous stem cells. Although the effects were most dramatic when rat testes depleted by cytotoxic treatments were used as recipients (Ogawa et al. 1999, Zhang et al. 2007), enhanced proliferation and differentiation of transplanted spermatogonia were also observed when mouse testes were used as recipients (Dobrinski et al. 2001, Ohmura et al. 2003, Kanatsu-Shinohara et al. 2004; R A Wang \& M L Meistrich, unpublished observations).

The mechanism by which somatic cells in rat testis are protected from damage if testosterone is suppressed at the time of cytotoxic exposure is not known. Neither is the mechanism by which testosterone suppression after cytotoxic exposure enhances the ability of the somatic elements of the testis to maintain the differentiation of spermatogonia. We had previously ruled out the possibility that the protective effect of hormonal suppression given before cytotoxic drug exposure was due to reduced delivery to the tissue or altered metabolism of the drug (Meistrich et al. 1994). We have recently shown that the block in spermatogonial differentiation in rats treated with cytotoxic agents is associated with the increased levels of interstitial edema in the testes (Porter et al. 2006). Based on data indicating that more rapid stimulation of recovery of
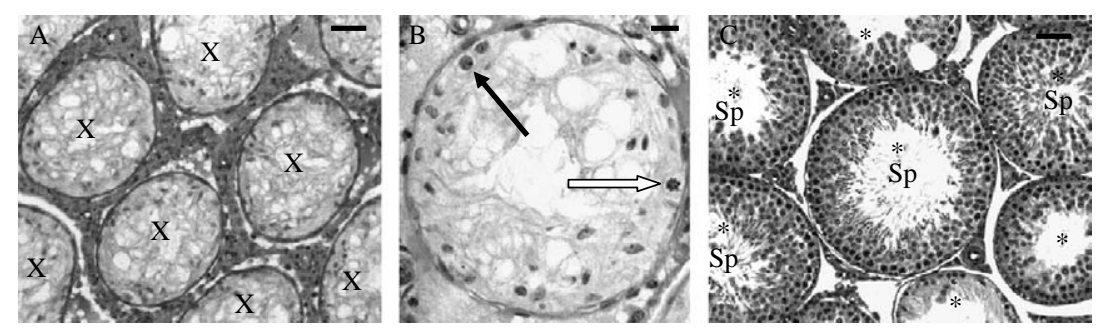

Figure 1 Photomicrographs of $\mathrm{LBNF}_{1}$ rat testes showing the radiation-induced block in the differentiation of spermatogonia $(\mathrm{A}$ and $\mathrm{B})$ and the reversal of this block by GnRH antagonist treatment. The testes were harvested 13 weeks after 5 Gy irradiation with or without GnRH antagonist treatment during weeks 3-7 after irradiation. Note that with no GnRH antagonist treatment all tubules are atrophic (X) and contain only Sertoli cells and type A spermatogonia (A), with normal (filled arrow) and dividing (open arrow) spermatogonia shown at higher magnification (B). With GnRH antagonist treatment, all tubules are repopulating $\left({ }^{*}\right)$ with mature spermatids in many of them (Sp) (C). (A and C) Bars $=50 \mu \mathrm{m}$ and (B) $20 \mu \mathrm{m}$. 
spermatogonial differentiation in irradiated rats was achieved by elimination of Leydig cells with ethane dimethane sulfonate than with total androgen ablation (G Shetty \& M T L Meistrich, unpublished data), we are analyzing the role of Leydig cells as targets for the testosterone-induced inhibition of spermatogonial differentiation in toxicant-treated rats.

\section{Experimental studies - females}

Studies have utilized mice, rats, and monkeys to investigate the protection against cyclophosphamide and radiation-induced ovarian damage. In these studies, the important target for which protection should be demonstrated was the primordial follicle, since it provides the reserve for the production of growing follicles and ova over a prolonged period of time. The protection of developing follicles would result only in a short-term enhancement of ovarian function, since these follicles are either recruited in a cyclic manner to undergo further development and ovulation or otherwise undergo atresia (McGee \& Hsueh 2000).

The mouse appears to be a good model to study the protective effects of various agents against cyclophosphamide damage, since the primordial follicles in mouse are moderately sensitive to killing by cyclophosphamide (Plowchalk \& Mattison 1991). An initial study claimed protection of mouse ovaries against cyclophosphamide with the synthetic steroid danazol, but that study examined only developing follicles, so the results do not bear on long-term protection of ovarian function (Budel et al. 1988). The protection of mouse primordial follicles from the damaging effects of cyclophosphamide was first reported in a study using a $\mathrm{GnRH}$ antagonist (Meirow et al. 2004). Although one study claimed protection using a $\mathrm{GnRH}$ agonist based on marginal statistical significance (Yuce et al. 2004), a subsequent study did show significant protection (Danforth et al. 2005). However, that study made the surprising observation that $\mathrm{GnRH}$ antagonists, even given without cyclophosphamide, had deleterious effects and depleted primordial follicles, which needs to be further investigated and confirmed (Gupta \& Flaws 2005).

By contrast, studies using rats for assessing the protection of ovarian function from cytotoxic agents such as cyclophosphamide did not yield any information on the long-term effects because rat primordial follicles are not sensitive to killing by cyclophosphamide (Ataya et al. 1985). The ability of GnRH agonist treatment to maintain the numbers of small follicles and fertility in cyclophosphamide-treated rats (Ataya et al. 1985, Ataya \& Ramahi-Ataya 1993) is therefore most likely a result of inhibition either of initial recruitment or of physiological loss of primordial follicles (Ataya et al. 1989). This observation that GnRH agonist treatment maintains the number of primordial follicles was surprising, since these follicles should be unaffected by gonadotropins, and other studies have failed to reproduce this observation (Jarrell et al. 1987, Bokser et al. 1990).

The one study in cyclophosphamide-treated monkeys showed that prolonged (1.5 years) GnRH agonist treatment reduced the rate of loss of primordial follicles (Ataya et al. 1995b). Although the results were interpreted as indicating that the $\mathrm{GnRH}$ agonist can protect primate ovaries against cyclophosphamide-induced damage, there was no control group treated with $\mathrm{GnRH}$ agonist alone, so the result may also represent $\mathrm{GnRH}$ agonist inhibition of recruitment of primordial follicles.

$\mathrm{GnRH}$ agonist has also been shown to prevent the doxorubicin-induced inhibition of estradiol production by granulosa cells in vitro (Imai et al. 2007). However, this study utilized granulosa cells from mature follicles, whereas the important target, the primordial follicles, may not have $\mathrm{GnRH}$ receptors.

Even less success has been reported with respect to hormonal protection of ovarian function from radiation. Radiation kills primordial follicles in all mammals studied, but those of the mouse are exquisitely sensitive and those of the rat are moderately sensitive (Baker 1978). In mice, gonadotropin reduction due to a hypogonadal mutation or $\mathrm{GnRH}$ antagonist treatment failed to protect primordial follicles from radiation (Gosden et al. 1997). Treatment with a GnRH agonist, but not with medroxyprogesterone acetate, partially protected against radiation-induced loss of primordial follicles in rats (Jarrell et al. 1987, 1989). No protection from radiation-induced loss of primordial follicles in monkeys was observed with GnRH agonist treatment (Ataya et al. 1995a).

In summary, very mixed results have been obtained in experimental studies regarding protection of primordial follicles from damage by cytotoxic agents by hormonal suppression. Some studies that claimed protection examined only growing follicles and thus could not support the notion that hormonal suppression protects the primordial follicles. Other studies showing that extended GnRH agonist treatment reduced the primordial follicle loss in animals treated with cytotoxic agents do not demonstrate that these follicles are protected but may be interpreted as inhibition of the normal initial recruitment of primordial follicles. Such a mechanism would not benefit women receiving GnRH agonist treatment during cytotoxic therapy; however, if the mechanism is valid, prolonged $\mathrm{GnRH}$ agonist treatment would preserve surviving primordial follicles for a longer period of time if the women want to delay childbearing. In cases where the protective effects have been observed against cyclophosphamide-induced depletion of primordial follicles in mice, the protection may involve direct effects of the $\mathrm{GnRH}$ analogs on the ovary or indirect effects of gonadotropin suppression such as reduced drug delivery due to a reduction of ovarian blood flow (Meirow et al. 2004). 
Table 1 Results of hormonal suppression treatments given before and during cytotoxic therapy on spermatogenic recovery in men.

\begin{tabular}{|c|c|c|c|c|c|}
\hline \multirow[b]{2}{*}{ Study } & \multirow[b]{2}{*}{ Disease } & \multirow[b]{2}{*}{ Cytotoxic therapy } & \multirow[b]{2}{*}{ Hormone treatment } & \multicolumn{2}{|c|}{ Recovery $^{a}$} \\
\hline & & & & Hormone treated & Controls \\
\hline Johnson et al. (1985) & Hodgkin's & MOPP 3-6 cycles & GnRH agonist & 1 of 5 & No controls \\
\hline Waxman et al. (1987) & Hodgkin's & MVPP, ChIVPP & GnRH agonist + testosterone & 0 of 20 & 0 of 10 \\
\hline Redman \& Bajorunas (1987) & Hodgkin's & MOPP $\sim 4$ cycles & Testosterone & $\approx 70 \%$ of $23^{b}$ & $\approx 70 \%$ of $22^{b}$ \\
\hline Fossa et al. (1988) & Testis Ca & $\begin{array}{l}\text { PVB, ADR/CY, } \\
\text { Radiation }\end{array}$ & Medroxyprogesterone & 0 of $4(2 \text { of } 12)^{\mathrm{c}}$ & 2 of $3(7 \text { of } 13)^{c}$ \\
\hline Kreuser et al. (1990) & Testis Ca & PVB & GnRH agonist & 6 of 6 & 8 of 8 \\
\hline Brennemann et al. (1994) & $\begin{array}{l}\text { Testis Ca } \\
\text { (Seminoma) }\end{array}$ & Radiation & $\mathrm{GnRH}$ agonist + antiandrogen & 12 of 12 & 8 of 8 \\
\hline Masala et al. (1997) & Nephritis & Cyclophosphamide & Testosterone & 5 of 5 & 1 of 5 \\
\hline
\end{tabular}

Chemotherapy regimens are as follows: MOPP, mechlorethamine vincristine, procarbazine, and prednisone; MVPP, mechlorethamine, vinblastine,procarbazine, and prednisone; ChIVPP, chlorambucil, vinblastine, procarbazine, and prednisone; PVB, cisplatin, vinblastine, and bleomycin; ADR/CY, adriamycin and cyclophosphamide.

${ }^{\text {a } F r a c t i o n ~ o f ~ m e n ~ r e c o v e r i n g ~ t e s t i c u l a r ~ f u n c t i o n ~ a s ~ a s s e s s e d ~ b y ~ r e s t o r a t i o n ~ o f ~ s p e r m ~ c o u n t s ~ t o ~ n o r m o s p e r m i c ~ l e v e l s ~ u n l e s s ~ o t h e r w i s e ~ n o t e d . ~}$

${ }^{\mathrm{b}}$ Actuarial recovery calculated by Kaplan-Meier analysis.

${ }^{\mathrm{c}}$ Recovery assessed by restoration of FSH levels to within the normal control range.

\section{Clinical trials - males}

Seven clinical trials have been performed in attempts to demonstrate the protection of spermatogenesis in humans by hormonal suppression treatment before and during cytotoxic therapy, but six indicated no protection (Table 1). Three of these trials involved patients treated for Hodgkin's lymphoma and three involved testicular cancer patients. Treatment with GnRH agonist resulted in only $20 \%$ of patients recovering sperm count after cessation of chemotherapy (Johnson et al. 1985). However, no concurrent control group of patients receiving similar regimens of chemotherapy without $\mathrm{GnRH}$ agonist was enrolled in this study. In another study, hormonal suppression with testosterone combined with GnRH agonist prior to and during chemotherapy was randomized with no hormonal suppression (Waxman et al. 1987), but none of the patients from the control and treated groups showed evidence of recovery of spermatogenesis at 1-3 years after completion of therapy. Suppression of gonadotropins and intratesticular testosterone levels with testosterone injections alone during treatment (Redman \& Bajorunas 1987) also did not provide gonadal protection benefit: $70 \%$ of the patients in both the treated and control group showed spermatogenic recovery at 3 years. Suppression of gonadotropins with medroxyprogesterone acetate during chemotherapy combined with radiotherapy did not improve the recovery of sperm count or normalize FSH levels, which was used as a surrogate for sperm count in patients in whom sperm counts were unavailable; indeed, they appeared to be lower in the patients receiving concurrent treatment with hormonal suppression than in controls (Fossa et al. 1988). Two more studies used GnRH agonist (Kreuser et al. 1990) or GnRH agonist plus an antiandrogen (cyproterone acetate) (Brennemann et al. 1994) prior to and for the duration of chemotherapy or radiation therapy respectively. In these studies, the chemotherapeutic regimen was only two courses of PVB and the gonadal dose of radiation was $0.2 \mathrm{~Gy}$, which allowed spontaneous recovery of sperm counts in all the control patients within 2 years. The time course of recovery of spermatogenesis after chemotherapy was identical for the groups of patients with or without $\mathrm{GnRH}$ agonist treatment. Although fluctuations in sperm counts made it difficult to determine whether the time course of recovery of spermatogenesis was affected by hormonal treatment, the time course of reduction of elevated FSH levels back to pretreatment values was similar in controls and patient groups treated with $\mathrm{GnRH}$ agonist and antiandrogen.

The one study that demonstrated hormonal treatment preservation of sperm production in men involved testosterone therapy of men who received cyclophosphamide as an immunosuppressive therapy for nephrotic syndrome (Masala et al. 1997). During the treatment, the testosterone suppressed gonadotropin levels and suppressed the completion of spermatogenesis. All but one of the men who received cyclophosphamide alone remained azoospermic 6 months after the end of immunosuppressive therapy, whereas sperm concentrations returned to normal in all five men who received cyclophosphamide in combination with testosterone therapy.

The one attempt to restore spermatogenesis by steroid hormonal suppression after cytotoxic therapy was also unsuccessful (Thomson et al. 2002). Seven men with azoospermia secondary to high-dose chemotherapy and/ or radiation therapy for leukemia or lymphoma in childhood were treated with medroxyprogesterone acetate combined with testosterone to suppress gonadotropin and likely intratesticular testosterone levels many years after the anticancer treatment. None of the men recovered any sperm production during the 24-week follow-up after the end of hormonal treatment. 
Even if the hormonal suppressive treatments that were successful in protecting and stimulating spermatogenic recovery in rats are applicable to human males, there may be many reasons for the unsuccessful outcomes of the aforementioned clinical trials. The use of testosterone or medroxyprogesterone either alone (Redman \& Bajorunas 1987, Fossa et al. 1988, Thomson et al. 2002) or combined with a GnRH analog (Waxman et al. 1987) is suboptimal given that, in animal studies, both of these steroids act directly on the testis to reduce the stimulatory effects of $\mathrm{GnRH}$ analogs on the recovery of spermatogenesis after cytotoxic damage (Shetty et al. 2002, 2004); however, this might not be as significant in humans, which have higher intratesticular androgen levels (Jarow et al. 2001). The number of patients and controls studied was small (Johnson et al. 1985) and the cancer therapies variable. Some treatment regimens were not sufficiently gonadotoxic to cause sterility (Kreuser et al. 1990, Brennemann et al. 1994); conversely some regimens may have delivered doses well above that needed to ablate all spermatogonial stem cells, since no evidence of spermatogenesis was observed in almost all patients even after many years (Johnson et al. 1985, Waxman et al. 1987, Thomson et al. 2002). Thus, the application of these procedures to humans remains uncertain.

\section{Clinical trials - females}

The greater proportion of prepubertal than of postpubertal women who maintain normal ovarian function after chemo- or radiotherapy (Horning et al. 1981) has been used to promote the concept that the ovary that is not stimulated by gonadotropins has a greater tolerance for these cytotoxic treatments. However, the larger store of follicles at the younger ages is an alternative explanation (Faddy et al. 1992). This alternate explanation is supported by the greater resistance of 20-yearold women than of 35-year-old women to induction of permanent ovarian failure from chemotherapy or radiation therapy (Meistrich et al. 2005).

Several studies reported by Blumenfeld's group (reviewed in (Blumenfeld \& Eckman 2005), Blumenfeld 2007), including a recent update of patients treated for Hodgkin lymphoma (Blumenfeld et al. 2008), showed that $7 \%$ of $\sim 125$ women treated with a GnRH agonist during chemotherapy exhibited premature ovarian failure characterized by hypergonadotropic amenorrhea, whereas $53 \%$ of 125 women in the control group treated with chemotherapy but not $\mathrm{GnRH}$ agonist (some concurrent with the $\mathrm{GnRH}$-treated group and some historical controls) suffered premature ovarian failure. None of these studies were randomized prospective trials, although attempts were made to demonstrate similar age ranges and chemotherapy and radiation doses in the $\mathrm{GnRH}$ agonist and control groups. In another study, adolescent girls (nine patients) received high-dose chemotherapy for bone marrow transplantation; those receiving $\mathrm{GnRH}$ agonist resumed menstrual cycles whereas those who were not treated with $\mathrm{GnRH}$ agonist had secondary amenorrhea (Pereyra Pacheco et al. 2001). In a recent study, 56 women were treated with a $\mathrm{GnRH}$ agonist and a synthetic estrogen; a control group did not take the treatment. The study reported that $90 \%$ of the gonadotropin-suppressed women recovered ovulatory and menstrual function versus $23 \%$ of those not treated (Castelo-Branco et al. 2007). The interpretation that protection occurred is, however, weakened by the fact that different treatments were given and age distributions in the control and treated groups were not comparable. Two phase II studies with adult breast cancer patients (100 patients in one and 29 patients in the other) suggested that a GnRH agonist treatment protected ovarian function, but the claims were based only on historical data in the literature and not a control group (Del Mastro et al. 2006, Recchia et al. 2006). In addition, an observational study of 145 patients reported that the patients taking oral contraceptives had only a $10 \%$ incidence of post-chemotherapy amenorrhea compared with $44 \%$ in the group not taking oral contraceptives (Behringer et al. 2005). One study utilized treatment with a $\mathrm{GnRH}$ antagonist, in addition to an agonist, during chemotherapy and reported good short-term recovery of menstrual cycles, but the study did not have a control group (Potolog-Nahari et al. 2007).

Although these studies indicate that suppression of gonadotropins and estrogen might be protective of ovarian function, none of them were prospective, randomized clinical trials, and hence must be considered inconclusive (Lee et al. 2006). There was only one randomized study on the effects of $\mathrm{GnRH}$ agonist on chemotherapy-induced sterility that involved 18 patients, and there was no protective effect (Waxman et al. 1987). However, the more recent suggestive evidence discussed above indicates that randomized clinical trials, several of which are in progress, need to be pursued.

\section{Relationship of experimental to human studies}

The results of studies of protection of long-term gonadal function by hormonal suppression in experimental animals and humans are summarized in Table 2. In males, hormonal suppression reliably stimulated recovery of spermatogenesis from surviving stem cells in rats but did not influence the survival of spermatogonial stem cells. In humans, only one of eight clinical trials showed that hormonal suppression enhanced subsequent gonadal function. In females, hormonal suppression provided mixed results on the protection of mouse primordial follicles from damage due to cyclophosphamide and rat primordial follicles from damage due to radiation. Several human clinical studies showed that GnRH agonist treatment produced good prolonged maintenance of ovarian function after chemotherapy, but this 
Table 2 Summary of effects of hormonal suppression on protection and stimulation of gonadal functions.

\begin{tabular}{|c|c|c|}
\hline Species & Effects of hormonal suppression in males & Effects of hormonal suppression in females \\
\hline Mouse & $\begin{array}{l}\text { Pretreatment suppression does not protect endogenous } \\
\text { spermatogenesis } \\
\text { Suppression moderately enhances spermatogenesis from } \\
\text { transplanted spermatogonia } \\
\text { Posttreatment suppression slightly stimulates recovery from } \\
\text { surviving stem cells }\end{array}$ & $\begin{array}{l}\text { Mixed results on protection of primordial follicles from } \\
\text { cyclophosphamide } \\
\text { No protection of primordial follicles from radiation }\end{array}$ \\
\hline Rat & $\begin{array}{l}\text { Pretreatment and posttreatment suppression } \\
\text { markedly stimulate spermatogenic recovery } \\
\text { from stem cells } \\
\text { Suppression markedly enhances spermatogenesis from } \\
\text { transplanted spermatogonia }\end{array}$ & $\begin{array}{l}\text { Mixed results on maintenance of primordial follicle number } \\
\text { during prolonged GnRH agonist treatment (independent of } \\
\text { cytotoxic exposure) } \\
\text { GnRH agonist, but not progestin, partially protects } \\
\text { primordial follicles from irradiation damage }\end{array}$ \\
\hline $\begin{array}{l}\text { Non-human } \\
\text { primate }\end{array}$ & $\begin{array}{l}\text { Neither pretreatment nor posttreatment suppression } \\
\text { enhance recovery of spermatogenesis after irradiation }\end{array}$ & $\begin{array}{l}\text { Prolonged GnRH agonist treatment maintains primordial } \\
\text { follicle numbers during cyclophosphamide treatment but } \\
\text { no proof of protection against cyclophosphamide-induced } \\
\text { damage } \\
\text { Suppression offers no protection from radiation-induced } \\
\text { loss of primordial follicles }\end{array}$ \\
\hline Human & $\begin{array}{l}\text { Suppression before and during therapy fails to protect } \\
\text { spermatogenesis from damage by cancer chemotherapy or } \\
\text { radiotherapy (six studies) } \\
\text { Suppression with testosterone before and during therapy } \\
\text { protected spermatogenesis from damage by } \\
\text { cyclophosphamide (one study) } \\
\text { Delayed posttreatment suppression failed to restore } \\
\text { spermatogenesis }\end{array}$ & $\begin{array}{l}\text { Several non-randomized studies (some with concurrent } \\
\text { controls) indicate that suppression markedly protects } \\
\text { against premature ovarian failure } \\
\text { One small randomized study showed no protective } \\
\text { effect of suppression }\end{array}$ \\
\hline
\end{tabular}

conclusion must be viewed with caution, as none of these studies were randomized clinical trials.

Experimental studies, particularly in rodents, are of great value in that they may be highly controlled, have larger sample sizes, and can be used to optimize treatments and elucidate mechanisms. Primate studies have greater variability and uncertainties and sample sizes are limited. The main question is what aspects of the rodent studies are applicable to the humans and what aspects are not. Since primates and rodents diverged 66 million years ago (Mya), there will be differences. It is also noteworthy that mouse and rat diverged 41 Mya, whereas humans and macaques diverged 23 Mya. Thus, significant differences are expected among rodents and between rodents and different primates. It is important to understand the mechanism of protection or stimulation of recovery by hormonal suppression in order to determine which individual steps in the process will be similar or different between rodents and primates.

Cytotoxic agents to which rodents and primates have similar sensitivities with respect to their effects on spermatogenesis are appropriate to utilize in experimental studies for extrapolation to men. Mouse and human spermatogenesis are both sensitive to certain alkylating agents (procarbazine, chlorambucil, and busulfan) and radiation as measured by stem cell killing and prolonged azoospermia respectively (Meistrich 1993). However, there are differences as spermatogonial stem cells in mice are sensitive to killing by doxorubicin (Adriamycin) but not cyclophosphamide, whereas cyclophosphamide, but not doxorubicin, strongly induces long-term azoospermia in humans. In rats, both radiation and procarbazine (Meistrich et al. 1999), but not cyclophosphamide (Meistrich et al. 1995), produce a prolonged block to spermatogonial differentiation.

In rats exposed to moderate doses of cytotoxic agents, the induction of a block in spermatogonial differentiation is a much more likely cause of prolonged azoospermia than is spermatogonial stem cell killing. The reversal of this block in spermatogonial differentiation appears to be the mechanism by which hormonal suppression protects or restores spermatogenesis in toxicant-exposed rats (Meistrich et al. 2000) and the occurrence of such a block should indicate whether hormonal suppression might stimulate spermatogenic recovery in another species. Although in many cases the seminiferous tubules in testicular biopsies taken from men with chemotherapy- or radiotherapy-induced azoospermia contain only Sertoli cells and no spermatogonia (Van Thiel et al. 1972), occasionally the presence of isolated spermatogonia have been observed at relatively long times after chemotherapy treatment (Kreuser et al. 1989). In addition, spontaneous recovery of spermatogenesis in some men more than 1 year after radiation (Hahn et al. 1982) or chemotherapy (Drasga et al. 1983) also implies a block in the differentiation of spermatogonia that survive these cytotoxic exposures. These results suggest that after some cytotoxic therapy regimens, there is a potentially reversible block to spermatogonial differentiation in men. It should be noted that there is no 
evidence of a similar spermatogonial block in monkeys (Boekelheide et al. 2005). The human data emphasize that the cytotoxic therapy regimens need to be carefully selected in these clinical trials from a range of regimens. To have a chance of success, doses of cytotoxic therapies should be chosen at which there is an appreciable block to spermatogonial differentiation but not killing of all stem spermatogonia.

Since many chemo- and radiotherapeutic regimens may result in complete killing of the stem spermatogonia and the hormonal methods do not protect these cells from cytotoxicity, consideration should be given to the applications of hormonal suppression in combination with spermatogonial transplantation. Cryopreservation of spermatogonia and autologous transplantation is considered a potential method for restoring spermatogenesis and possibly rescuing fertility after chemo- or radiotherapy (Orwig \& Schlatt 2005). Hormonal suppression could restore the somatic environment in human testes sufficiently to promote the ability of transplanted stem spermatogonia to develop, as was the case with rat testes (Zhang et al. 2007).

It is also important to consider whether the molecular and cellular effects of hormonal suppression are similar in humans and rats. Although the basic processes by which GnRH analogs suppress gonadotropin and testosterone levels and induce a block in the completion of spermatogenesis in normal adult males are similar in rodents and primates, there are quantitative differences. Whereas in rats and humans, GnRH antagonist reduced intratesticular testosterone concentrations to about $2 \%$ of that observed in controls (Shuttlesworth et al. 2000, Matthiesson et al. 2005); in macaques it only reduced intratesticular testosterone concentrations to $28 \%$ of control (Zhengwei et al. 1998). Despite the less marked reduction in intratesticular testosterone levels, spermatogenesis was blocked at the B spermatogonial stage by $\mathrm{GnRH}$ antagonist treatment of the primates (Zhengwei et al. 1998) compared with the round spermatid stage in rats (Kangasniemi et al. 1996b). In humans, the block in spermatogenesis was also largely at the B spermatogonial levels, but later germ cells to the round spermatid stage were still produced at $20 \%$ of control levels (Matthiesson et al. 2005). The restimulation of spermatogonial differentiation by hormonal suppression in rats may be dependent upon the ability of germ cells to develop to the spermatocyte stage during the testosterone suppression, and hence might occur in men. Further germ cell differentiation in the presence of suppressed testosterone can be induced in human testes by treatment with FSH (Matthiesson et al. 2006).

To extrapolate the results of studies of protection of ovarian function from rodent systems to women, it is important that the cytotoxic mechanism of chemotherapy action on the follicles in the experimental model be similar to that in women. The mouse model seems to be appropriate for investigation of the protection against cyclophosphamide, as primordial follicles in the mouse and women are moderately sensitive and show a doseresponsive loss (Plowchalk \& Mattison 1991) or a dosedependent increase in sustained amenorrhea (Boumpas et al. 1993) respectively, after exposure to increasing doses of cyclophosphamide. Although primordial follicles in both rodents and humans are killed by radiation, the exquisite sensitivity of murine primordial follicles to death by apoptosis and the relative radioresistance of human primordial follicles make this a less comparable model system (Baker 1978).

It is also important to elucidate the mechanisms by which hormonal suppression protects primordial follicles in female mice from cytotoxic therapy in order to better determine how to apply the results to women and select an appropriate hormonal treatment for maximal protection.

It needs to be determined whether or not suppression of gonadotropins is involved in the protective mechanism. All successful experimental and clinical trials utilized $\mathrm{GnRH}$ analogs, and almost exclusively agonists rather that antagonists. $\mathrm{GnRH}$ receptors are present in the ovary so that the action of GnRH might be at the local level rather than in the pituitary. Possible differential effect of $\mathrm{GnRH}$ agonists and antagonists on oocytes and granulosa cells also need to be investigated (Yano et al. 1997).

Since currently there is no evidence that the primordial follicle is a direct target for the action of gonadotropins or $\mathrm{GnRH}$ analogs, effects that are mediated at the level of the whole ovary should be considered. The possibility that the protective effect on mouse primordial follicle against chemotherapy could result in a decline in ovarian blood flow during $\mathrm{GnRH}$ analog treatment induced ovarian quiescence (Meirow et al. 2004), as had been observed in human females (Dada et al. 2001), needs further investigation.

Another step that needs further study is the mechanism of death of the follicle after chemotherapy or radiation, which in the mouse is a result of apoptosis (Morita et al. 2000). It is important to determine whether or not GnRH analog treatment affects the apoptotic machinery in oocytes and/ or granulosa cells, particularly the pregranulosa cells in primordial follicles, and whether it renders them less sensitive to the induction of apoptosis, and if it does, that it does not also protect the tumor cells from apoptotic death.

Based on the recent reports that the primordial follicle pool may be dynamic and that there is a mechanism for replenishment of primordial follicles in adult mice (Johnson et al. 2004), the replenishment of the primordial follicle pool may have to be considered, in addition to its maintenance. Although this work remains controversial and, if valid, its extension to human is uncertain, this phenomenon should be considered when trying to explain the effects of hormonal suppression on the numbers of primordial follicles after exposure to cytotoxic cancer therapies. 
In conclusion, the most immediate need is for randomized prospective clinical trials to test whether the promising results of previous non-randomized clinical studies on the use of $\mathrm{GnRH}$ agonist treatment to protect ovarian function during cancer chemotherapy can be supported by a rigorous test. In addition, mechanistic studies in appropriate animal models are needed to determine which aspects of the beneficial effects of hormonal suppression on maintenance of both male and female fertility in select animal models may be applicable to human and to predict hormonal regimens that may offer maximal protection.

\section{Declaration of interest}

There is no conflict of interest that would prejudice the impartiality of this scientific work.

\section{Funding}

The research done in our laboratories and the writing of this review were supported by Research Grant ES-08075 from the National Institute of Environmental Health Sciences (National Institutes of Health), USA.

\section{References}

Ataya K \& Ramahi-Ataya A 1993 Reproductive performance of female rats treated with cyclophosphamide and/or LHRH agonist. Reproductive Toxicology $7229-235$.

Ataya KM, McKanna JA, Weintraub AM, Clark MR \& LeMaire WJ 1985 A luteinizing hormone-releasing hormone agonist for the prevention of chemotherapy-induced ovarian follicular loss in rats. Cancer Research 45 3651-3656.

Ataya KM, Tadros M \& Ramahi A 1989 Gonadotropin-releasing hormone agonist inhibits physiologic ovarian follicular loss in rats. Acta Endocrinologica 121 55-60.

Ataya K, Pydyn E, Ramahi-Ataya A \& Orton CG 1995a Is radiation-induced ovarian failure in rhesus monkeys preventable by luteinizing hormonereleasing hormone agonists?: preliminary observations Journal of Clinical Endocrinology and Metabolism 80 790-795.

Ataya K, Rao LV, Lawrence E \& Kimmel R 1995b Luteinizing hormonereleasing hormone agonist inhibits cyclophosphamide-induced ovarian follicular depletion in rhesus monkeys. Biology of Reproduction 52 365-372.

Baker TG 1978 Effects of ionizing radiations on mammalian oogenesis: a model for chemical effects. Environmental Health Perspectives 24 $31-37$.

Behringer K, Breuer K, Reineke T, May M, Nogova L, Klimm B, Schmitz T, Wildt L, Diehl V \& Engert A 2005 Secondary amenorrhea after Hodgkin's lymphoma is influenced by age at treatment, stage of disease, chemotherapy regimen, and the use of oral contraceptives during therapy: a report from the German Hodgkin's Lymphoma Study Group. Journal of Clinical Oncology 23 7555-7564.

Blanchard KT, Lee J \& Boekelheide K 1998 Leuprolide, a gonadotropinreleasing hormone agonist, reestablishes spermatogenesis after 2,5hexanedione-induced irreversible testicular injury in the rat, resulting in normalized stem cell factor expression. Endocrinology 139 236-244.

Blumenfeld Z 2007 How to preserve fertility in young women exposed to chemotherapy? The role of $\mathrm{GnRH}$ agonist cotreatment in addition to cryopreservation of embrya, oocytes, or ovaries. Oncologist 12 1044-1054.
Blumenfeld Z \& Eckman A 2005 Preservation of fertility and ovarian function and minimization of chemotherapy-induced gonadotoxicity in young women by GnRH-a. Journal of the National Cancer Institute Monographs 40-43.

Blumenfeld Z, Avivi I, Eckman A, Epelbaum R, Rowe JM \& Dann EJ 2008 Gonadotropin-releasing hormone agonist decreases chemotherapyinduced gonadotoxicity and premature ovarian failure in young female patients with Hodgkin lymphoma. Fertility and Sterility 89 166-173.

Boekelheide K \& Hall SJ 1991 2,5-Hexanedione exposure in the rat results in long-term testicular atrophy despite the presence of residual spermatogonia. Journal of Andrology 12 18-26.

Boekelheide K, Schoenfeld H, Hall SJ, Weng CCY, Shetty G, Leith J, Harper J, Sigman M, Hess DL \& Meistrich ML 2005 Gonadotropinreleasing hormone antagonist (cetrorelix) therapy fails to protect nonhuman primates (macaca arctoides) from radiation-induced spermatogenic failure. Journal of Andrology 26 222-234.

Bokser L, Szende B \& Schally AV 1990 Protective effects of D-Trp $6^{-}$ luteinising hormone-releasing hormone microcapsules against cyclophosphamide-induced gonadotoxicity in female rats. British Journal of Cancer 61 861-865.

Boumpas DT, Austin HA III, Vaughan EM, Yarboro CH, Klippel JH \& Balow JE 1993 Risk for sustained amenorrhea in patients with systemic lupus erythematosus receiving intermittent pulse cyclophosphamide therapy. Annals of Internal Medicine 119 366-369.

Brennemann W, Brensing KA, Leipner N, Boldt I \& Klingmuller D 1994 Attempted protection of spermatogenesis from irradiation in patients with seminoma by D-tryptophan-6 luteinizing hormone releasing hormone. Clinical Investigator 72 838-842.

Budel V, Kiss R, de Launoit Y, Danguy A, Atassi G, Pasteels JL \& Paridaens R 1988 Prevention of ovarian damage induced by cyclophosphamide in adult female mice by hormonal manipulations. Journal of Reproduction and Fertility 84 625-633.

Castelo-Branco C, Nomdedeu B, Camus A, Mercadal S, Martinez de Osaba MJ \& Balasch J 2007 Use of gonadotropin-releasing hormone agonists in patients with Hodgkin's disease for preservation of ovarian function and reduction of gonadotoxicity related to chemotherapy. Fertility and Sterility 87 702-705.

Chapman RM \& Sutcliffe SB 1981 Protection of ovarian function by oral contraceptives in women receiving chemotherapy for Hodgkin's disease. Blood 58 849-851.

Crawford BA, Spaliviero JA, Simpson JM \& Handelsman DJ 1998 Testing the gonadal regression-cytoprotection hypothesis. Cancer Research $\mathbf{5 8}$ 5105-5109.

da Cunha MF, Meistrich ML \& Nader S 1987 Absence of testicular protection by a gonadotropin releasing hormone analog against cyclophosphamide-induced testicular cytotoxicity in the mouse. Cancer Research 47 1093-1097.

Dada T, Salha O, Allgar V \& Sharma V 2001 Utero-ovarian blood flow characteristics of pituitary desensitization. Human Reproduction $\mathbf{1 6}$ 1663-1670.

Danforth DR, Arbogast LK \& Friedman CI 2005 Acute depletion of murine primordial follicle reserve by gonadotropin-releasing hormone antagonists. Fertility and Sterility 83 1333-1338.

Delic JI, Bush C \& Peckham MJ 1986 Protection from procarbazine-induced damage of spermatogenesis in the rat by androgen. Cancer Research $\mathbf{4 6}$ 1909-1914.

Dobrinski I, Ogawa T, Avarbock MR \& Brinster RL 2001 Effect of the GnRHagonist leuprolide on colonization of recipient testes by donor spermatogonial stem cells after transplantation in mice. Tissue and Cell 33 200-207.

Drasga RE, Einhorn LH, Williams SD, Patel DN \& Stevens EE 1983 Fertility after chemotherapy for testicular cancer. Journal of Clinical Oncology 1 179-183.

Faddy MJ, Gosden RG, Gougeon A, Richardson SJ \& Nelson JF 1992 Accelerated disappearance of ovarian follicles in mid-life: implications for forecasting menopause. Human Reproduction 7 1342-1346.

Fossa SD, Klepp O \& Norman N 1988 Lack of gonadal protection by medroxyprogesterone acetate-induced transient medical castration during chemotherapy for testicular cancer. British Journal of Urology 62 449-453. 
Glode LM, Robinson J \& Gould SF 1981 Protection from cyclophosphamide-induced testicular damage with an analogue of gonadotropinreleasing hormone. Lancet 1 1132-1134.

Goodpasture JC, Bergstrom K \& Vickery BH 1988 Potentiation of the gonadotoxicity of Cytoxan in the dog by adjuvant treatment with luteinizing hormone-releasing hormone agonist. Cancer Research $\mathbf{4 8}$ 2174-2178.

Gosden RG, Wade JC, Fraser HM, Sandow J \& Faddy MJ 1997 Impact of congenital or experimental hypogonadotrophism on the radiation sensitivity of the mouse ovary. Human Reproduction 12 2483-2488.

Gupta RK \& Flaws JA 2005 Gonadotropin-releasing hormone $(\mathrm{GnRH})$ analogues and the ovary: do $\mathrm{GnRH}$ antagonists destroy primordial follicles? Fertility and Sterility 83 1339-1342.

Hahn EW, Feingold SM, Simpson L \& Batata M 1982 Recovery from aspermia induced by low-dose radiation in seminoma patients. Cancer $50337-340$.

Hild SA, Meistrich ML, Blye RP \& Reel JR 2001 Lupron depot prevention of antispermatogenic/antifertility activity of the indenopyridine, CDB-4022, in the rat. Biology of Reproduction 65 165-172.

Horning SJ, Hoppe RT, Kaplan HS \& Rosenberg SA 1981 Female reproductive potential after treatment for Hodgkin's disease. New England Journal of Medicine 304 1377-1382.

Imai A, Sugiyama M, Furui T, Tamaya T \& Ohno T 2007 Direct protection by a gonadotropin-releasing hormone analog from doxorubicin-induced granulosa cell damage. Gynecologic and Obstetric Investigation 63 102-106.

Jarow JP, Chen H, Rosner TW, Trentacoste S \& Zirkin BR 2001 Assessment of the androgen environment within the human testis: minimally invasive method to obtain intratesticular fluid. Journal of Andrology 22 640-645.

Jarrell J, YoungLai EV, McMahon A, Barr R, O'Connell G \& Belbeck L 1987 Effects of ionizing radiation and pretreatment with [D-Leu6,des-Gly10] luteinizing hormone-releasing hormone ethylamide on developing rat ovarian follicles. Cancer Research 47 5005-5008.

Jarrell J, YoungLai EV, McMahon A, Barr R, O'Connell G \& Belbec L 1989 The effect of medroxyprogesterone acetate (Provera) on ovarian radiosensitivity. American Journal of Obstetrics and Gynecology 160 990-994.

Jégou B, Velez de la Calle JF \& Bauche F 1991 Protective effect of medroxyprogesterone acetate plus testosterone against radiationinduced damage to the reproductive function of male rats and their offspring. PNAS $\mathbf{8 8} 8710-8714$.

Johnson DH, Linde R, Hainsworth JD, Vale W, Rivier J, Stein R, Flexner J, Welch RV \& Greco FA 1985 Effect of a luteinizing hormone releasing hormone agonist given during combination chemotherapy on posttherapy fertility in male patients with lymphoma: preliminary observations. Blood 65 832-836.

Johnson J, Canning J, Kaneko T, Pru JK \& Tilly JL 2004 Germline stem cells and follicular renewal in the postnatal mammalian ovary. Nature 428 145-150.

Kamischke A, Kuhlmann M, Weinbauer GF, Luetjens M, Yeung C-H, Kronholz HL \& Nieschlag E 2003 Gonadal protection from radiation by GnRH antagonist or recombinant human FSH: a controlled trial in a male nonhuman primate (Macaca fascicularis). Journal of Endocrinology 179 183-194.

Kanatsu-Shinohara M, Morimoto T, Toyokuni S \& Shinohara T 2004 Regulation of mouse spermatogonial stem cell self-renewing division by the pituitary gland. Biology of Reproduction 70 1731-1737.

Kangasniemi M, Wilson G, Parchuri N, Huhtaniemi I \& Meistrich ML 1995 Rapid protection of rat spermatogenic stem cells against procarbazine by treatment with a gonadotropin-releasing hormone antagonist ( $\mathrm{Nal}-\mathrm{Glu}$ ) and an antiandrogen (flutamide). Endocrinology 136 2881-2888.

Kangasniemi M, Huhtaniemi I \& Meistrich ML 1996a Failure of spermatogenesis to recover despite the presence of $\mathrm{A}$ spermatogonia in the irradiated $\mathrm{LBNF}_{1}$ rat. Biology of Reproduction 54 1200-1208.

Kangasniemi M, Dodge $K$, Pemberton AE, Huhtaniemi I \& Meistrich ML 1996 Suppression of mouse spermatogenesis by a gonadotropin-releasing hormone antagonist and antiandrogen: failure to protect against radiationinduced gonadal damage. Endocrinology 137 949-955.

Kreuser ED, Kurrle E, Hetzel WD, Heymer B, Porzsolt R, Hautmann R, Gaus W, Schlipf U, Pfeiffer EF \& Heimpel H 1989 Reversible germ cell toxicity after aggressive chemotherapy in patients with testicular cancer: results of a prospective study. Klinische Wochenschrift 67 367-378.
Kreuser ED, Hetzel WD, Hautmann R \& Pfeiffer EF 1990 Reproductive toxicity with and without LHRHA administration during adjuvant chemotherapy in patients with germ cell tumors. Hormone and Metabolic Research 22 494-498.

Lee SJ, Schover LR, Partridge AH, Patrizio P, Wallace WH, Hagerty K, Beck LN, Brennan LV \& Oktay K 2006 American Society of Clinical Oncology recommendations on fertility preservation in cancer patients. Journal of Clinical Oncology 24 2917-2931.

Lewis RW, Dowling KJ \& Schally AV 1985 D-tryptophhan-6 analog of luteinizing hormone-releasing hormone as a protective agent against testicular damage caused by cyclophosphamide in baboons. PNAS 82 2975-2979.

Manabe F, Takeshima H \& Akaza H 1997 Protecting spermatogenesis from damage induced by doxorubicin using the luteinizing hormone-releasing hormone agonist leuprorelin: an image analysis study of a rat experimental model. Cancer 79 1014-1021.

Masala A, Faedda R, Alagna S, Satta A, Chiarelli G, Rovasio PP, Ivaldi R, Taras MS, Lai E \& Bartoli E 1997 Use of testosterone to prevent cyclophosphamide-induced azoospermia. Annals of Internal Medicine 126 292-295.

Del Mastro L, Catzeddu T, Boni L, Bell C, Sertoli MR, Bighin C, Clavarezza M, Testa D \& Venturini M 2006 Prevention of chemotherapy-induced menopause by temporary ovarian suppression with goserelin in young, early breast cancer patients. Annals of Oncology 17 74-78.

Matthiesson KL, Stanton PG, O'Donnell L, Meachem SJ, Amory JK, Berger R, Bremner WJ \& McLachlan RI 2005 Effects of testosterone and levonorgestrel combined with a 5alpha-reductase inhibitor or gonadotropin-releasing hormone antagonist on spermatogenesis and intratesticular steroid levels in normal men. Journal of Clinical Endocrinology and Metabolism 90 5647-5655.

Matthiesson KL, McLachlan RI, O'Donnell L, Frydenberg M, Robertson DM, Stanton PG \& Meachem SJ 2006 The relative roles of folliclestimulating hormone and luteinizing hormone in maintaining spermatogonial maturation and spermiation in normal men. Journal of Clinical Endocrinology and Metabolism 91 3962-3969.

McGee EA \& Hsueh AJ 2000 Initial and cyclic recruitment of ovarian follicles. Endocrine Reviews 21 200-214.

Meirow D, Assad G, Dor J \& Rabinovici J 2004 The GnRH antagonist cetrorelix reduces cyclophosphamide-induced ovarian follicular destruction in mice. Human Reproduction 19 1294-1299.

Meistrich ML 1982 Quantitative correlation between testicular stem cell survival, sperm production, and fertility in the mouse after treatment with different cytotoxic agents. Journal of Andrology 3 58-68.

Meistrich ML 1993 Effects of chemotherapy and radiotherapy on spermatogenesis. European Urology 23 136-142.

Meistrich ML 1994 Failure to demonstrate hormonal protection of chemotherapy-induced fertility reduction in female rats. Reproductive Toxicology 8 277-280.

Meistrich ML \& Kangasniemi M 1997 Hormone treatment after irradiation stimulates recovery of rat spermatogenesis from surviving spermatogonia. Journal of Andrology 18 80-87.

Meistrich ML \& Shetty G 2003 Inhibition of spermatogonial differentiation by testosterone. Journal of Andrology 24 135-148.

Meistrich ML, Wilson G, Ye W-S, Kurdoglu B, Parchuri N \& Terry NHA 1994 Hormonal protection from procarbazine-induced testicular damage is selective for survival and recovery of stem spermatogonia. Cancer Research 54 1027-1034.

Meistrich ML, Parchuri N, Wilson G, Kurdoglu B \& Kangasniemi M 1995 Hormonal protection from cyclophosphamide-induced inactivation of rat stem spermatogonia. Journal of Andrology 16 334-341.

Meistrich ML, Wilson G, Zhang Y, Kurdoglu B \& Terry NHA 1997 Protection from procarbazine-induced testicular damage by hormonal pretreatment does not involve arrest of spermatogonial proliferation. Cancer Research 57 1091-1097.

Meistrich ML, Wilson G \& Huhtaniemi I 1999 Hormonal treatment after cytotoxic therapy stimulates recovery of spermatogenesis. Cancer Research 59 3557-3560.

Meistrich ML, Wilson G, Kangasniemi M \& Huhtaniemi I 2000 Mechanism of protection of rat spermatogenesis by hormonal pretreatment: stimulation of spermatogonial differentiation after irradiation. Journal of Andrology 21 464-469. 
Meistrich ML, Wilson G, Shuttlesworth G, Huhtaniemi I \& Reissmann T $2001 \mathrm{GnRH}$ agonists and antagonists stimulate recovery of fertility in irradiated LBNF1 rats. Journal of Andrology 22 809-817.

Meistrich ML, Wilson G, Porter KL, Huhtaniemi I, Shetty G \& Shuttlesworth G 2003 Restoration of spermatogenesis in dibromochloropropane (DBCP)-treated rats by hormone suppression. Toxicological Sciences 76 418-426.

Meistrich ML, Vassilopoulou-Sellin R \& Lipshultz LI 2005 Gonadal dysfunction. In Cancer: Principles and Practice of Oncology, edn 7, pp 2560-2574. Eds VT DeVita, S Hellman \& SA Rosenberg. Philadelphia: Lippincott Williams and Wilkins.

Meistrich ML, Zhang Z, Porter KL, Bolden-Tiller OU \& Shetty G 2007 Prevention of adverse effects of cancer treatment on the germline. In Male-Mediated Developmental Toxicity, pp 114-123. Eds D Anderson \& MH Brinkworth. Cambridge: Royal Society of Chemistry.

Morita Y, Perez GI, Paris F, Miranda SR, Ehleiter D, Haimovitz-Friedman A, Fuks Z, Xie Z, Reed JC, Schuchman EH et al. 2000 Oocyte apoptosis is suppressed by disruption of the acid sphingomyelinase gene or by sphingosine-1-phosphate therapy. Nature Medicine 6 1109-1114.

Morris ID \& Shalet SM 1990 Protection of gonadal function from cytotoxic chemotherapy and irradiation. Ballieres Clinical Endocrinology and Metabolism 4 97-118.

Nonomura M, Okada K, Hida S \& Yoshida O 1991 Does a gonadotropinreleasing hormone analogue prevent cisplatin-induced spermatogenic impairment? An experimental study in the mouse Urological Research 19 135-140.

Nseyo UO, Huben RP, Klioze SS \& Pontes JE 1985 Protection of germinal epithelium with luteinizing hormone-releasing hormone analogue. Journal of Urology 134 187-190.

Ogawa T, Dobrinski I \& Brinster RL 1999 Recipient preparation is critical for spermatogonial transplantation in the rat. Tissue and Cell 31 461-472.

Ohmura M, Ogawa T, Ono $M$, Dezawa $M$, Hosaka $M$, Kubota $Y$ \& Sawada H 2003 Increment of murine spermatogonial cell number by gonadotropin-releasing hormone analogue is independent of stem cell factor c-kit signal. Biology of Reproduction 68 2304-2313.

Orwig KE \& Schlatt S 2005 Cryopreservation and transplantation of spermatogonia and testicular tissue for preservation of male fertility. Journal of the National Cancer Institute Monographs 34 51-56.

Parchuri N, Wilson G \& Meistrich ML 1993 Protection by gonadal steroid hormones against procarbazine-induced damage to spermatogenic function in LBNF1 hybrid rats. Journal of Andrology 14 257-266.

Pereyra Pacheco B, Mendez Ribas JM, Milone G, Fernandez I, Kvicala R, Mila T, Di Noto A, Contreras Ortiz O \& Pavlovsky S 2001 Use of GnRH analogs for functional protection of the ovary and preservation of fertility during cancer treatment in adolescents: a preliminary report. Gynecologic Oncology 81 391-397.

Plowchalk DR \& Mattison DR 1991 Reproductive toxicity of cyclophosphamide in the C57BL/6N mouse: 1 . Effects on ovarian structure and function. Reproductive Toxicology 6 411-421.

Pogach LM, Lee Y, Gould S, Giglio W \& Huang HFS 1988 Partial prevention of procarbazine induced germinal cell aplasia in rats by sequential GnRH antagonist and testosterone administration. Cancer Research 48 4354-4360.

Porter KL, Shetty G \& Meistrich ML 2006 Testicular edema is associated with spermatogonial arrest in irradiated rats. Endocrinology 147 1297-1305.

Potolog-Nahari C, Fishman A \& Cohen I 2007 Protection of ovarian function and fertility using a combination of gonadotropin-releasing hormone $(\mathrm{GnRH})$ agonist and $\mathrm{GnRH}$ antagonist during cancer treatment in young females. Gynecological Endocrinology 23 290-294.

Recchia F, Saggio G, Amiconi G, Di Blasio A, Cesta A, Candeloro G \& Rea S 2006 Gonadotropin-releasing hormone analogues added to adjuvant chemotherapy protect ovarian function and improve clinical outcomes in young women with early breast carcinoma. Cancer 106 514-523.
Redman JR \& Bajorunas DR 1987 Suppression of germ cell proliferation to prevent gonadal toxicity associated with cancer treatment. In Workshop on Psychosexual and Reproductive Issues Affecting Patients with Cancer. pp 90-94. New York: American Cancer Society.

Setchell BP, Ploen L \& Ritzen EM 2001 Reduction of long-term effects of local heating of the testis by treatment of rats with a GnRH agonist and an anti-androgen. Reproduction 122 255-263.

Setchell BP, Ploen L \& Ritzen EM 2002 Effect of local heating of rat testes after suppression of spermatogenesis by pretreatment with a $\mathrm{GnRH}$ agonist and an anti-androgen. Reproduction 124 133-140.

Shetty G, Wilson G, Hardy MP, Niu E, Huhtaniemi I \& Meistrich ML 2002 Inhibition of recovery of spermatogenesis in irradiated rats by different androgens. Endocrinology 143 3385-3396.

Shetty G, Weng CCY, Bolden-Tiller OU, Huhtaniemi I, Handelsman DJ \& Meistrich ML 2004 Effects of medroxyprogesterone and estradiol on the recovery of spermatogenesis in irradiated rats. Endocrinology $\mathbf{1 4 5}$ 4461-4469.

Shetty G, Weng CC, Meachem SJ, Bolden-Tiller OU, Zhang Z, Pakarinen P, Huhtaniemi I \& Meistrich ML 2006 Both testosterone and FSH independently inhibit spermatogonial differentiation in irradiated rats. Endocrinology 147 472-482.

Shuttlesworth GA, de Rooij DG, Huhtaniemi I, Reissmann T, Russell LD, Shetty G, Wilson G \& Meistrich ML 2000 Enhancement of A spermatogonial proliferation and differentiation in irradiated rats by GnRH antagonist administration. Endocrinology 141 37-49.

Van Thiel DH, Sherins RJ, Myers GH \& De Vita VT 1972 Evidence for a specific seminiferous tubular factor affecting follicle-stimulating hormone secretion in man. Journal of Clinical Investigation 51 1009-1019.

Thomson AB, Anderson RA, Irvine DS, Kelnar CJH, Sharpe RM \& Wallace WHB 2002 Investigation of suppression of the hypothalamicpituitary-gonadal axis to restore spermatogenesis in azoospermic men treated for childhood cancer. Human Reproduction 17 1715-1723.

Udagawa K, Ogawa T, Watanabe T, Yumura Y, Takeda M \& Hosaka M 2001 $\mathrm{GnRH}$ analog, leuprorelin acetate, promotes regeneration of rat spermatogenesis after severe chemical damage. International Journal of Urology 8 615-622.

Waxman JH, Ahmed R, Smith D, Wrigley PFM, Gregory W, Shalet S, Crowther D, Rees LH, Besser GM, Malpas JS et al. 1987 Failure to preserve fertility in patients with Hodgkin's disease. Cancer Chemotherapy and Pharmacology 19 159-162.

Weissenberg R, Lahav M, Raanani P, Singer R, Regev A, Sagiv M, Giler S \& Theodor E 1995 Clomiphene citrate reduces procarbazine-induced sterility in a rat model. British Journal of Cancer 71 48-51.

Yano T, Yano N, Matsumi H, Morita Y, Tsutsumi O, Schally AV \& Taketani Y 1997 Effect of luteinizing hormone-releasing hormone analogs on the rat ovarian follicle development. Hormone Research 48 (Supplement 3) $35-41$.

Yuce MA, Balkanli Kaplan P, Gucer F, Doganay L, Altaner S, Canda T \& Yardim T 2004 Prevention of cyclophosphamide-induced ovarian damage by concomitant administration of $\mathrm{GnRHa}$ in mice: a dosedependent relationship? European Journal of Gynaecological Oncology 25 628-631.

Zhang Z, Shao S \& Meistrich M 2007 The radiation-induced block in spermatogonial differentiation is due to damage to the somatic environment, not the germ cells. Journal of Cellular Physiology 211 149-158.

Zhengwei Y, Wreford NG, Schlatt S, Weinbauer GF, Nieschlag E \& McLachlan RI 1998 Acute and specific impairment of spermatogonial development by $\mathrm{GnRH}$ antagonist-induced gonadotrophin withdrawal in the adult macaque (Macaca fascicularis). Journal of Reproduction and Fertility 112 139-147.

Received 4 March 2008

First decision 10 April 2008

Accepted 9 May 2008 